\title{
Treatment of gingival recession with coronally advanced Flap - A case report
}

Singh $\mathbf{R}^{1}$

'Associate Professor, KMC BDS Programme, Kathmandu Medical College Teaching Hospital, Kathmandu, Nepal

\section{Abstract}

Extensive gingival recession associated with cervical abrasions is common. Several different surgical and/or restorative therapies have been proposed to correct these lesions. This paper reports the treatment of multiple gingival recessions associated with shallow root caries. The procedure involved utilization of coronally advanced flap. At the postoperative follow-up visits, the success of the surgical approach was confirmed by the absence of tooth sensitivity and presence of gingival tissue with normal colour, texture and contour. After 12 months of follow-up, the clinical conditions were stable with satisfactory root coverage and periodontal health. An excellent aesthetical outcome was achieved and the patient was satisfied with the outcome.

Key words: Coronally Advanced Flap, Gingival Recession, Root coverage

\section{Introduction}

G ingival recession is defined as the displacement of the soft tissue margin apical to the cementoenamel junction ${ }^{1}$ and is a frequent clinical feature in populations with both $\operatorname{good}^{2,3}$ and poor $^{4}$ standards of oral hygiene. Toothbrush trauma is considered the most common precipitating factor in initiation and progression of non-inflammatory, localized gingival recession, and is associated with several variables found to be erroneous and traumatic: tooth brushing frequency ${ }^{5}$, use of hard bristle brushes ${ }^{6}$ and brushing technique ${ }^{7}$. Another important risk factor for gingival recession is progressive plaque accumulation, which can induce periodontal destruction. This normally causes initial attachment loss as periodontal pockets, but can also appear as initial gingival recession ${ }^{8,9}$.

Gingival recession can render patients aesthetically conscious. Besides, it can cause tooth sensitivity, cervical abrasion, and increased susceptibility to root caries and leads to poor oral hygiene. This necessitates alleviation of gingival recession in a predictable manner. Clinicians are challenged to achieve outcomes that meet these exacting standards, and therefore need a sound, clinically

Address for correspondence
Dr. Rita Singh
Oracare Periodontal Clinic
114, SamaMarg, Kamalpokhari,
Kathmandu
E-mail: s.rita2000@gmail.com

oriented and scientifically supported decision-making process to plan the therapeutic approach, to predict the outcome and, finally, to achieve it. The functional aspects of root coverage may be controversial, but the cosmetic aspect and satisfaction is not debatable.

Evidence shows that a coronally advanced flap alone in many instances results in complete root coverage and is stable over time ${ }^{10}$. A coronally advanced flap is less invasive for the patient, requires less chair-time and probably less surgical skill. It would therefore be desirable to use a coronally advanced flap approach when indicated. It has been hypothesized that a coronally advanced flap approach alone could be successfully applied when the residual gingiva is thick ${ }^{11}$ and wide ${ }^{12}$, although existing evidence does not support this hypothesis in full. It can be used in treating single or multiple recession defects.

\section{Case Report}

A 35-year-old female was referred to periodontics specialist complaining of the unaesthetic appearance and tooth sensitivity of her maxillary front teeth. During the clinical examination, it was noted that there were multiple Miller's class $I^{13}$ gingival recessions in teeth numbers 11 and 21. Gingival recessions were associated with cervical abrasions and root caries (Figures 1 and 2). The teeth presented shallow probing depth with bleeding on probing. 
The patient was first submitted to initial preparation comprising scaling, root planing and oral hygiene instructions. After 10 days, she was scheduled for root coverage procedure with coronally advanced flap. This was the technique chosen as she demonstrated more than $3 \mathrm{~mm}$ of attached gingiva and thick gingival biotype.

After antisepsis and anaesthesia, an intrasulcular incision was made with a surgical blade on the buccal aspect of the involved teeth. Two oblique vertical releasing incisions were made lateral to the recession defects starting at a point apical to the interdental papillae extending into the alveolar mucosa. The distance between the coronal extension of the vertical incision and the crest of the interdental papillae was approximately equal to the anticipated coronal displacement of the flap, to minimize tissue overlapping in the interdental area. A trapezoidal mucoperiosteal flap was raised 1 to $2 \mathrm{~mm}$ apical to the crest of the bone to expose the dehiscence. Then a partial thickness dissection was carried out apically from this level leaving the underlying periosteum in place. A mesiodistal and apical dissection parallel to the vestibular lining mucosa was performed to release residual muscle tension and facilitate the passive coronal displacement of the flap. The papillae were de-epithelialized and the flap then displaced at least $1 \mathrm{~mm}$ coronal to the cemento-enamel junction. The root caries were excavated using a spoon excavator (figure 3).

Suturing of oblique releasing incision was performed with 4-0 silk sutures as described by Allen and Miller ${ }^{14}$ in an apico-coronal direction before suturing the papillae. This allowed for positioning of the gingiva without tension. Additional interrupted sutures were placed to close the oblique releasing incisions in the alveolar mucosa. The coronal, mesial and distal extremities ties

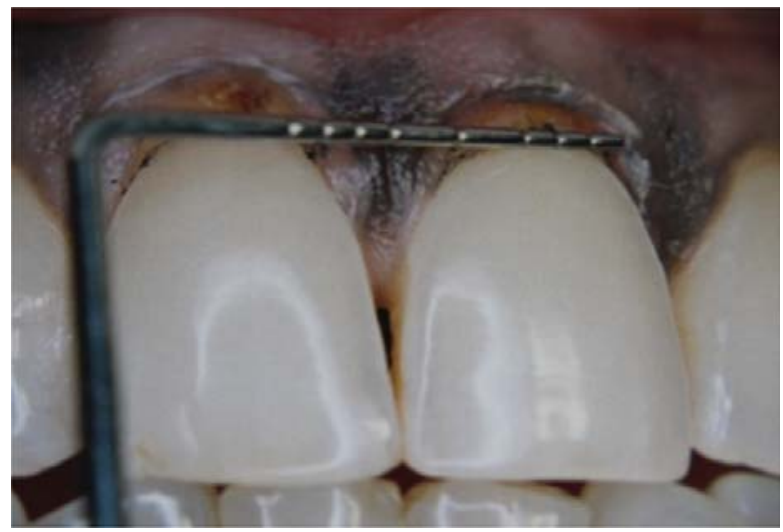

of the flap were secured with two single sutures placed in the interdental areas (Fig 4). Tin foil and periodontal dressing were placed over the sites.

After surgery, the patient received pain relieving medication (Ibuprofen 400mg every 6 hours) when needed, antibiotic (Amoxicillin 500 mg every 8 hours for 7 days) and chemical plaque control $(0.12 \%$ Chlorhexidine gluconate rinse - every 12 hours for 14 days). The pack and sutures were removed after 10 days. Three weeks after surgery, she was instructed to resume mechanical tooth cleaning using a soft toothbrush and a careful rolltechnique. She was called for follow up weekly for four weeks, once a month for 3 months and once every 3 months up to 12 months.

Complete root coverage was obtained and the results were maintained. The patient reported to be completely satisfied with the aesthetical outcome. Her tooth sensitivity was also totally abolished. At 6 (fig 5) and 12 months (Fig 6) after the procedure, the periodontal tissues presented normal colour, texture and contouring.

\section{Discussion}

The amount and thickness of keratinized tissue is generally thought to influence the outcome of root coverage: thick tissues and large amounts of residual keratinized tissue are 'perceived' as favourable. Many clinicians select a coronally advanced flap or a sliding flap when the residual keratinized tissue is well represented, or place a graft under the flap when keratinized tissue is insufficient in thickness and width ${ }^{15}$. However, there is limited evidence to support this approach.

A clinical study ${ }^{11}$ tested the influence of flap thickness following coronally advanced flap procedures. The results indicate that flap thickness is significantly $(P<0.0001)$ associated with root coverage. A flap thickness of

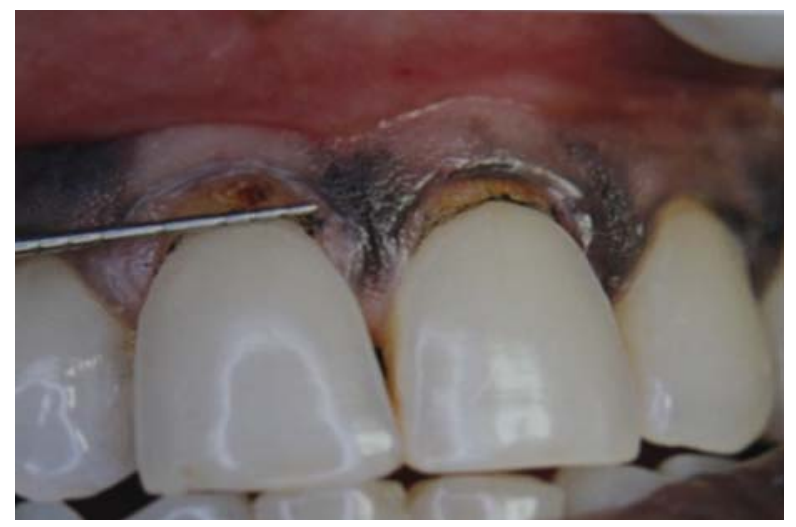

Fig. 1 and 2: Gingival recessions on maxillary central incisors associated with root abrasions and caries. 


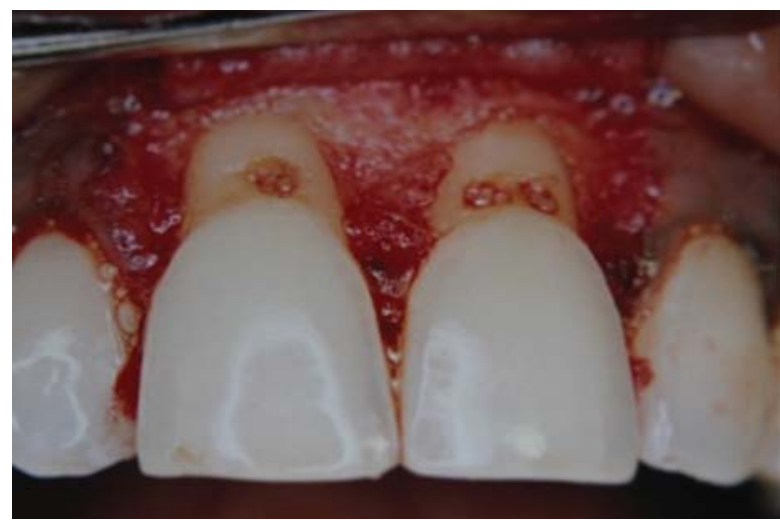

Fig. 3: Flap reflected and root caries excavated

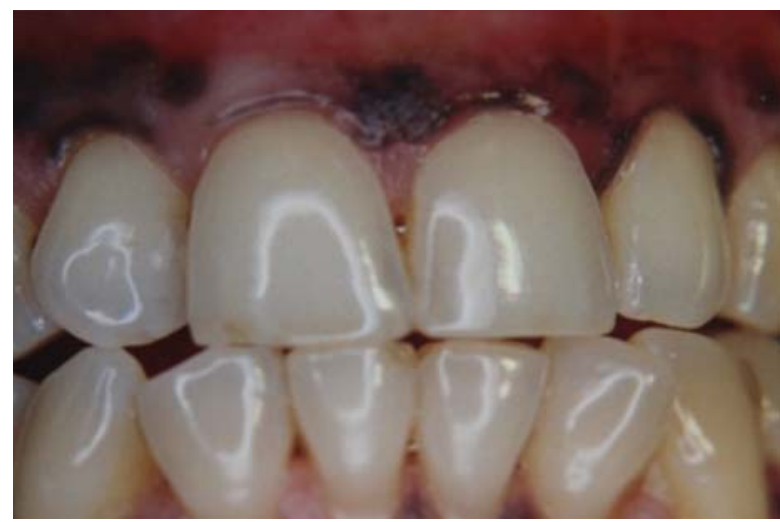

Fig 5: The 6 months clinical outcome.

$>0.8 \mathrm{~mm}$ was associated with complete root coverage, while a flap thickness of $<0.8 \mathrm{~mm}$ was associated with partial root coverage. In addition, linear regression analysis showed that with each increase in thickness of $0.1 \mathrm{~mm}$, recession was reduced by approximately $0.2 \mathrm{~mm}$ in all treated sites. Therefore, $0.8 \mathrm{~mm}$ can be considered as the critical flap thickness above which the expected clinical outcome should be complete root coverage when using a coronally advanced flap alone.

Another study ${ }^{12}$ evaluated the relationship between root coverage and baseline amount of keratinized tissue in laterally positioned and coronally advanced flaps. Multiple logistic regression analysis showed a statistically significant relationship between complete root coverage and the amount of keratinized tissue lateral to the gingival defects: the greater the amount of keratinized tissue, the greater the percentage of root coverage.

Many studies and recent systematic reviews showed the importance of baseline recession depth in the treatment

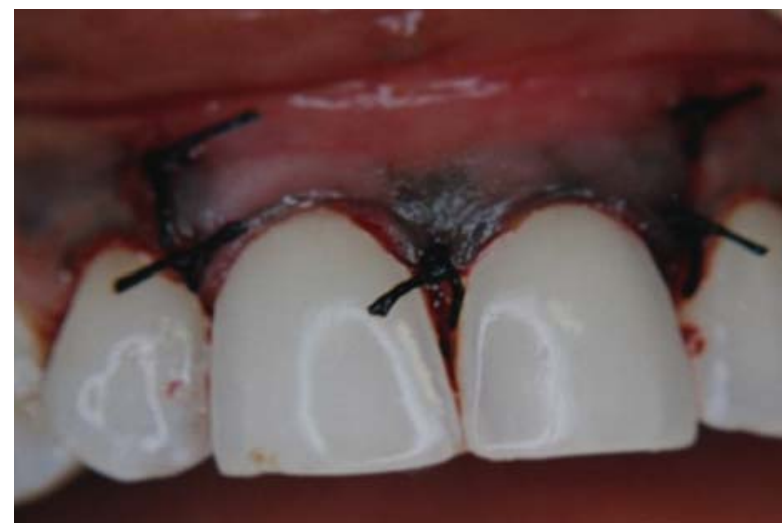

Fig. 4: Coronally advanced flap on gingival recessions. The trapezoidal flap has been sutured coronally to the cemento-enamel junction.

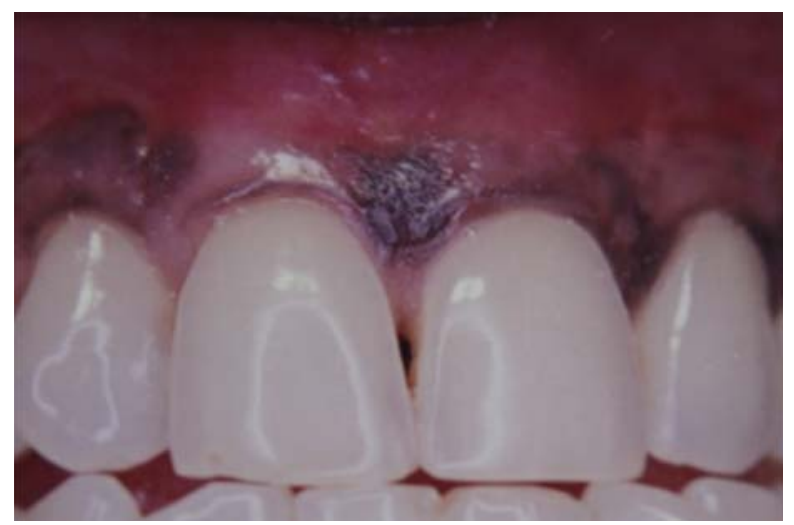

Fig. 6: The 12 months clinical outcome.

outcome. The results of the meta-analyses of controlled and randomized clinical trials published by Roccuzzo et al. ${ }^{16}$ and Clauser et al. ${ }^{17}$ showed a relationship between the initial recession depth and the final outcome of the surgical procedure, reporting that 'greater baseline recession depths were always associated with decreased complete root coverage'.

Following coronally advanced flap therapy of single recession defects, Pini Prato et al. ${ }^{18}$ reported that the gingival margin, sutured, on average, $1 \mathrm{~mm}$ coronal to the cemento-enamel junction, remained stable at week 1 , but shifted apically from weeks 2 to 4 , uncovering the cemento-enamel junction in $60 \%$ of the sites with an average shift of $1.5 \pm 0.6 \mathrm{~mm}$. From week 4 to week 12 after the procedure, the gingival margin remained stable.

Coronally advanced flap can be utilized when indicated. Unfortunately, the key information - to be able to forecast when coronally advanced flap will be successful - is still missing. Many 'experts' support the hypothesis 
that therapy with coronally advanced flap alone can be successfully applied when the residual gingiva is thick and wide. Accordingly, the adjunctive use of a graft could be restricted to sites with thin and narrow residual gingiva. A potential alternative is the use of enamel matrix derivative.

\section{References}

1. American Academy of Periodontology. Glossary of periodontal terms. 3rd ed. Chicago: The American Academy of Periodontology; 1992.

2. Löe $H$, Anerud A, Boysen $H$. The natural history of periodontal disease in man: prevalence, severity, and extent of gingival recession. J Periodontol. 1992;63:489-95.

3. Serino G, Wennström JL, Lindhe J, Eneroth L. The prevalence and distribution of gingival recession in subjects with a high standard of oral hygiene. J Clin Periodontol.1994;21:57-63.

4. Baelum V, Fejerskov O, Karring T. Oral hygiene, gingivitis and periodontal breakdown in adult Tanzanians. J Periodontal Res. 1986;21:221-32.

5. Vehkalahti M. Occurrence of gingival recession in adults. J Periodontol. 1989;60:599-603.

6. Khocht A, Simon G, Person P, Denepitiya JL. Gingival recession in relation to history of hard toothbrush use. J Periodontol.1993;64:900-5.

7. Checchi L, Daprile G, Gatto MR,Pelliccioni GA. Gingival recession and toothbrushing in an Italian school of dentistry: a pilot study. J Clin Periodontol.1999;26:276-80.

8. Yoneyama T, Okamoto $\mathrm{H}$, Lindhe J, Socransky SS, Haffajee AD. Probing depth, attachment loss and gingival recession:findings from a clinical examination in Ushiku, Japan. J Clin Periodontol.1988;15:581-91.

9. Heitz-Mayfield LJA, Schätzle $M$, Löe $H$, Bürgin W, Anerud A, Boysen H, Lang NP. Clinical course of chronic periodontitis II. Incidence, characteristics and time of occurrence of the initial periodontal lesion. J Clin Periodontol. 2003;30:902-8.

10. Cairo F, Pagliaro U, Nieri M.Treatment of gingival recession with coronally advanced flap procedures: a systematic review. J Clin Periodontol. 2008;35:136-62.

\section{Conclusions}

This case report indicates that teeth with multiple gingival recessions, associated with shallow root caries can be successfully treated by the coronally advanced flap. When used in indicated cases, this root coverage technique is less invasive for the patient, requires less chair-time and less surgical skill.

11. Baldi C, Pini Prato GP, Pagliaro U, Nieri M, Saletta D, Muzzi L, Cortellini P. Coronally advanced flap procedure for root coverage. Is flap thickness a relevant predictor to achieve root coverage? A 19case series. J Periodontol. 1999;70:1077-84.

12. Zucchelli G, Cesari C, Amore C, Montebugnoli L, De Sanctis M. Laterally moved, coronally advanced flap: a modified surgical approach for isolated recessiontype defects. J Periodontol. 2004:75:1734-41.

13. Miller PD Jr. A classification of marginal tissue recession. Int J Periodontotics Restorative Dent. 1985;5:8-13.

14. Allen EP, Miller PD. Coronal positioning of existing gingiva: short term results in the treatment of shallow marginal tissue recession. J Periodontol. 1989:60:316-9.

15. Wennström JL, Zucchelli G. Increased gingival dimensions. A significant factor for successful outcome of root coverage procedures? A 2-year prospective clinical study. J Clin Periodontol. 1996;23:770-7.

16. Roccuzzo M, Bunino M, Needleman I, Sanz M. Periodontal plastic surgery for treatment of localized gingival recessions: a systematic review. J Clin Periodontol. 2002;29:178-94.

17. Clauser C, Nieri M, Franceschi D, Pagliaro U, Pini Prato GP. Evidence-based mucogingival therapy. Part 2: Ordinary and individual patient data metaanalyses of surgical treatment of recession using complete root coverage as the outcome variable. J Periodontol. 2003;74:741-56.

18. Pini Prato GP, Baldi C, Pagliaro U, Nieri M, Saletta D, Rotundo R, Cortellini P. Coronally advanced flap procedure for root coverage. Treatment of root surface: root planing versus polishing. J Periodontol. 1999;70:1064-76. 